\title{
Comparative study of mechanical stresses in human limb bones
}

\author{
Doina Drăgulescu,' Lucian Rusu,' Vlad Morcovescu,' Cris Precup² \\ 'Politehnica University of Timişoara, Timişoara, Romania; ${ }^{2}$ Vasile Goldiş West University of Arad, Arad, Romania
}

\begin{abstract}
This research studies the upper and lower limb bones of elderly persons. The measurements of compressive, tensile and bending forces were performed on 147 specimens: 72 in a compression trial, 21 in a tensile trial and 54 in a bending trial. Bones were extracted from 38 cadavers (60-70-years-old at the time of death). Experimental protocols were developed to minimise the possible errors in obtaining the data. All results were statistically processed. There was a significant difference between the results of both the tensile and bending trials and the compression trial $(p=0.08)$. Significant differences were observed between the results of the compression test in proximal versus distal ends of the bones (femur, tibia and humerus). After the removal of outlying results, an F-test analysis was performed on all remaining values, establishing different correlation levels between the groups of results. These results were compared with those published by other researchers.
\end{abstract}

Keywords: compression test, tensile test, bending test, human limbs

\section{Introduction}

Bones are inhomogeneous materials whose mechanical properties depend on composition and structure, and which are different in the transverse and longitudinal directions. The mechanical properties also depend on the age of the subject, ie they are significantly reduced in aged persons (Lindahl 1976; Carter and Spengler 1978; Hansson and Roos 1980; Panjabi and White 2001), where the bones can be damaged even at a low speed of loading (corresponding to normal walking). The damage predominately occurs in regions characterised by decreased mineral content, which are at the proximal ends of the bones. Here, the accentuated demineralisation is affected by the ageing process and skeletal disease (eg osteoporosis) (Carter and Spengler 1978; Dvir 2000). In those regions, the bone is mostly trabecular.

Because bone structure is dissimilar in the transverse and longitudinal directions, it exhibits different mechanical properties when loaded in these different directions. The literature is rich in observations about the variation of mechanical properties (Pope and Outwater 1972; Reilly et al 1974; Bonfield and O'Connor 1978; Dvir 2000). The correlation between a bone's density and its mechanical properties has also been studied (Abendschein and Hyatt 1970; Wall et al 1979).

The main goal of this study was to determine the ultimate stresses in compression, tensile and bending tests for bones of the upper and lower limbs of old persons. The objectives were: (1) to obtain experimental results on real bones to complete the databases found in the actual literature; (2) to compare the mechanical behaviour of different bones; (3) to compare the mechanical behaviour of different parts of the same bone; (4) to find analytical correlations for the prognosis of mechanical resistance to different types of tests; and (5) to verify the data and the correlations in the literature concerning the bones' mechanical behaviours.

\section{Methods}

The experimental study was performed on many human limb bones to determine their mechanical properties. The cadavers used were from farmers aged 60-70 years and people whose bones were poor in minerals due to substandard living conditions. Bone density was determined by CT (Siemens Computer Tomograph Somatom Plus 4 , Laboratory of Images Processing, Politehnica University of Timişoara, Romania). The CT gave density values in the range of $0.31 \pm 0.03 \mathrm{~kg} / \mathrm{cm}^{3}(\mathrm{p}=0.01)$ on 12 bone pieces (cut mid-zone) that were randomised during the bending test. For the pieces cut from the bone ends, as used in the compression trials, the density values were found to be in the range of $0.175 \pm 0.01(p=0.03)$. The variation in density between these two locations is about $16.67 \%$ (the density at the bone ends being lower).

Correspondence: Doina Drăgulescu, Politehnica University of Timişoara, Mihai Viteazu Blvd nr I, 1900 Timişoara, Romania; tel/fax +40256403637; email ddrag@cmpicsu.utt.ro 
The bone preparation protocol included the following stages: the cadavers were injected with $10 \%$ formaldehyde solution and stored in the same solution for 4-6 months. After normal dissection, the lower and upper limb segments were disarticulated and placed in pure water for $48 \mathrm{~h}$. The water was replaced 3-4 times to decrease the formaldehyde content, which was obstructing the riving of the soft tissues. The bones were then boiled, completely covered, for 18$24 \mathrm{~h}$ in pure water until the soft tissues had been removed. Finally, the cleaned bones were washed consecutively in: warm water, $19 \% \mathrm{NaOH}$ solution and warm water, and sealed in light-tight containers.

Different mechanical trials were performed on a universal testing machine with a strain rate of $0.001 \mathrm{~s}^{-1}$ (Lanyon and Hampson 1975; Panjabi and White 2001). The failure forces and the cross-section bone areas were measured in order to compute the failure stress, the only way to obtain accurate information about the bones' mechanical behaviours.

To prepare the trial specimens, the original bones were roughly cut and the ends removed (Figure 1). The second process was different for each mechanical test. For the compression trial, the specimens were cut from the proximal
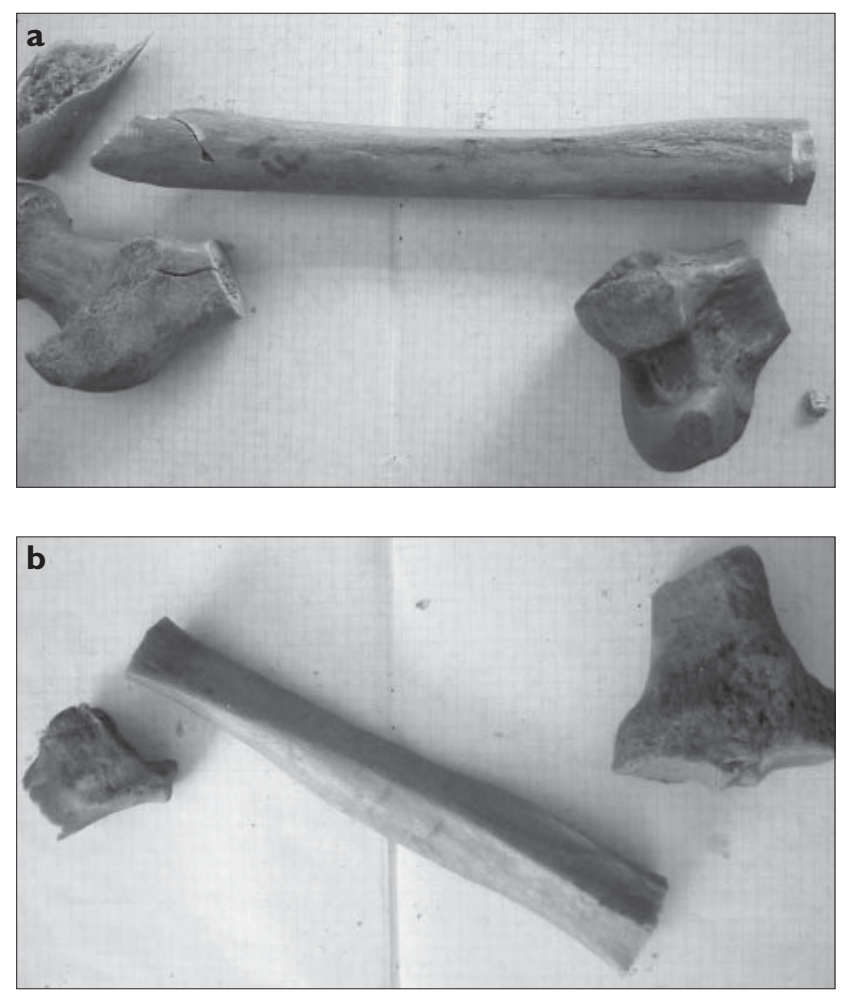

Figure I (a) Femur - specimen nr I. (b) Tibia - specimen nr I.

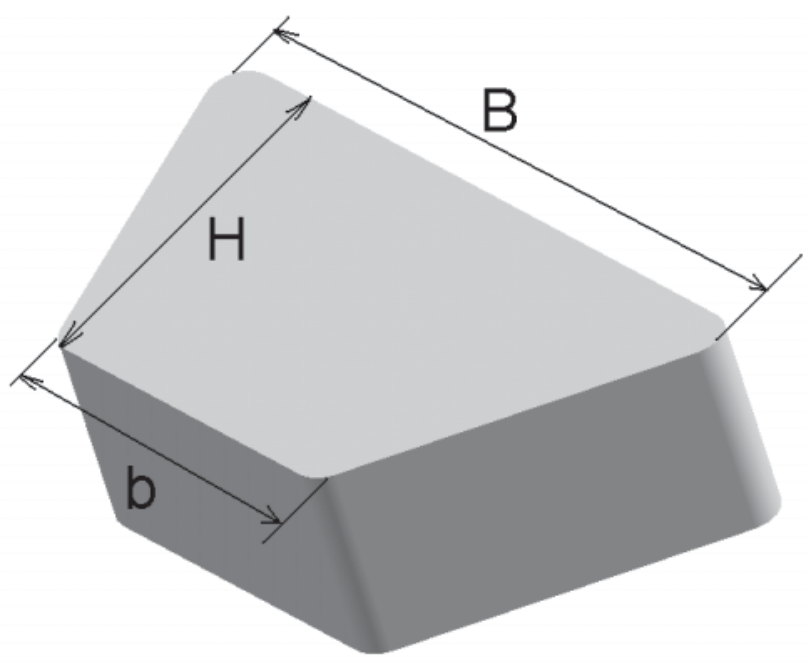

Figure 2 Compression specimen approximate shape (trapeze).

and distal bone ends. All specimens were 20-mm long, and for the stress calculation the actual cross-section dimensions were measured.

The cross-section areas were calculated by approximating the actual shape as a trapeze (Figure 2). For the tensile and bending trials, the specimens with variable length (but longer than $150 \mathrm{~mm}$, ie the distance between the supports in the bending test) were cut mid-zone.

Except for the femur, whose cross-section shape of the central zone is quasi-circular, the bones' geometric shapes were considered triangular (Figure 3), and the edges were measured.

Examples of the measurements of the bones' geometry are given in Table 1. The corresponding areas are a result of the shape adopted.

The compression and tensile tests were axially performed (Figure 4), and the bending tests were performed transversally (Figure 5). In the last trial, the specimens were supported at both ends and loaded in their midsection (threepoint loading).

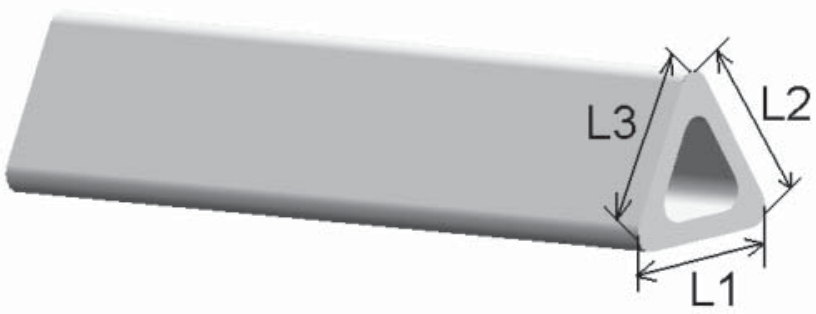

Figure 3 Tensile and bending specimen approximate shape (triangular). 
Table I Geometry of bone cross sections (trapeze for compression specimens, triangle for tensile and bending specimens) ${ }^{\mathrm{a}}$

\begin{tabular}{|c|c|c|c|c|c|c|c|c|}
\hline Specimen $n r$ & $\begin{array}{r}b \\
(\mathrm{~mm})\end{array}$ & $\begin{array}{r}B \\
(\mathrm{~mm})\end{array}$ & $\begin{array}{r}H \\
(\mathrm{~mm})\end{array}$ & $\begin{array}{l}A_{\text {trapeze }} \\
\quad\left(\mathrm{mm}^{2}\right)\end{array}$ & $\begin{array}{r}L 1 \\
(\mathrm{~mm})\end{array}$ & $\begin{array}{r}L 2 \\
(\mathrm{~mm})\end{array}$ & $\begin{array}{r}L 3 \\
(\mathrm{~mm})\end{array}$ & $\begin{array}{l}A_{\text {triangle }} \\
\quad\left(\mathrm{mm}^{2}\right)\end{array}$ \\
\hline \multicolumn{9}{|l|}{ Femur } \\
\hline 1 & 43.0 & 83.0 & 59.0 & 3717 & 29.5 & 30.0 & 30.0 & 299.35 \\
\hline 2 & 41.0 & 77.0 & 65.0 & 3835 & 27.5 & 29.0 & 27.0 & 269.76 \\
\hline 3 & 37.0 & 67.0 & 61.0 & 3172 & 28.0 & 26.5 & 27.5 & 262.52 \\
\hline 4 & 37.0 & 77.0 & 56.0 & 3192 & 28.5 & 26.0 & 27.5 & 262.52 \\
\hline \multicolumn{9}{|l|}{ Tibia } \\
\hline 1 & 38.0 & 41.9 & 41.6 & 1661.92 & 19.0 & 27.0 & 25.0 & 211.5157 \\
\hline 2 & 38.7 & 46.3 & 43.0 & 1827.50 & 25.0 & 22.5 & 29.5 & 238.88 \\
\hline 3 & 35.9 & 42.6 & 44.8 & 1758.40 & 23.5 & 25.5 & 20.5 & 204.84 \\
\hline 4 & 41.0 & 48.8 & 49.7 & 2231.53 & 30.5 & 26.5 & 31.5 & 294.35 \\
\hline 5 & 33.2 & 42.0 & 43.6 & 1639.36 & 18.5 & 23.5 & 17.0 & 160.22 \\
\hline 6 & 38.0 & 41.9 & 41.6 & 1661.92 & 19.0 & 27.0 & 25.0 & 211.51 \\
\hline
\end{tabular}

${ }^{\mathrm{a}}$ Refer to Figures 2 and 3.

The stress values for each specimen were calculated by dividing the recorded force values by the cross-section areas and were processed using statistical calculations. The raw experimental data were first analysed by using Chauvenet criteria, and, as a consequence, the outlying results were removed.

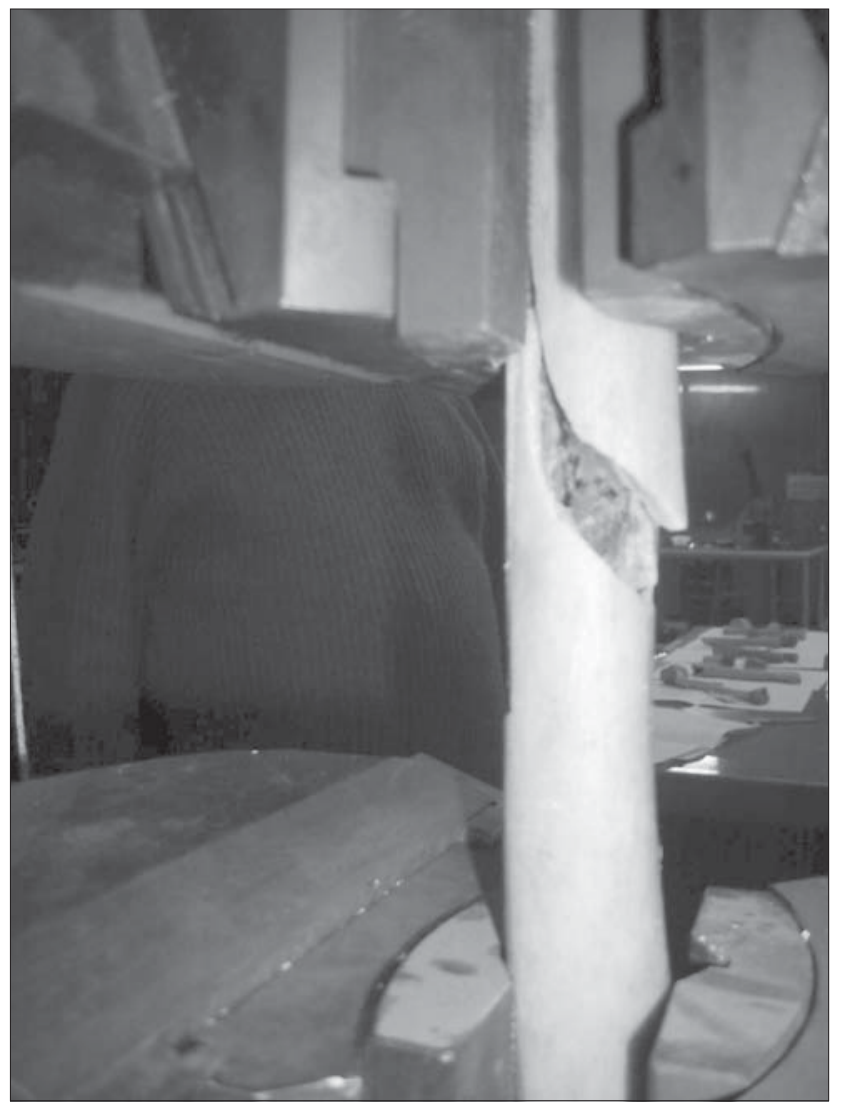

Figure 4 Tensile test of femur - specimen $n r 2$.

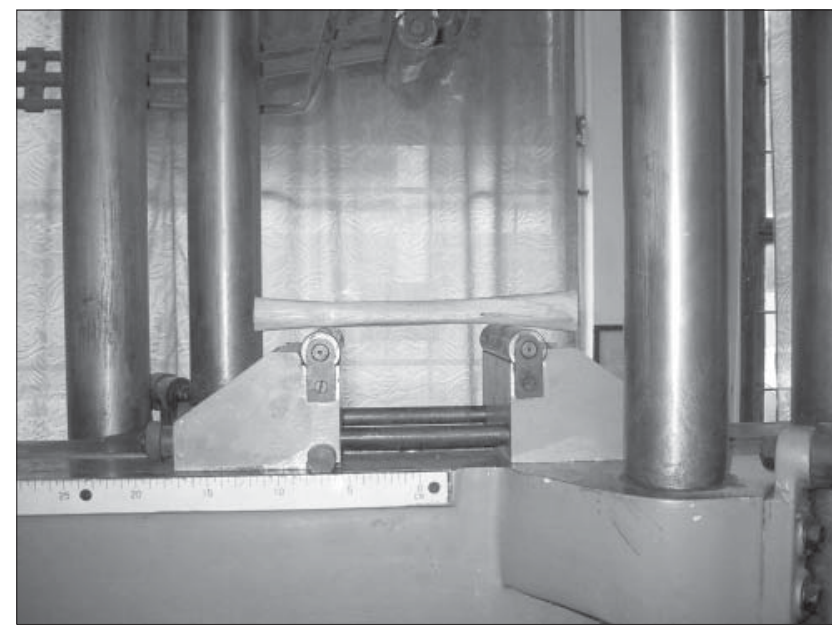

Figure 5 Bending test of femur.

\section{Results}

The strongest and most complex bones (femur, tibia and humerus) were trialled for compression, tensile strength and bending. Ulna and radius were trialled for bending because they have a lesser role in compression. After the application of Chauvenet criteria, the results were processed and the following parameters calculated: average value, standard deviation, average confidence (with a confidence level of $90 \%$ ) and variance (Table 2).

By comparing the average resulting stress values given by the compression trial of femur, tibia and humerus (Figure 6), the following was observed: (1) at the distal ends, the values were greater than those at the proximal ends of the same bone, the difference being very significant for tibia and humerus; and (2) at the distal ends of different bones the values were not significantly different $(p=0.05)$. 
Table 2 Basic statistical estimators for femur, tibia and humerus

\begin{tabular}{|c|c|c|c|c|c|c|}
\hline Bone & Test & $\begin{array}{l}\text { Number of } \\
\text { specimens }^{\mathrm{a}}\end{array}$ & $\begin{array}{r}\text { Average value } \\
(\mathrm{MPa})\end{array}$ & $\begin{array}{l}\text { Standard } \\
\text { deviation }\end{array}$ & $\begin{array}{r}\text { Confidence } \\
\text { interval }\end{array}$ & Variance \\
\hline \multirow[t]{4}{*}{ Femur } & Compression - proximal end & 12 & 1.6005 & 1.0364 & 1.7046 & 1.0740 \\
\hline & Compression - distal end & 12 & 1.6828 & 1.1403 & 1.8756 & 1.3002 \\
\hline & Tensile & 7 & 4.4168 & 1.9974 & 1.1488 & 3.9895 \\
\hline & Bending & 11 & 4.0218 & 2.3957 & 1.9703 & 5.7395 \\
\hline \multirow[t]{4}{*}{ Tibia } & Compression - proximal end & 13 & 0.6506 & 0.3706 & 0.0740 & 0.1373 \\
\hline & Compression - distal end & 13 & 1.5224 & 0.7172 & 0.8251 & 0.5144 \\
\hline & Tensile & 6 & 1.4872 & 0.4914 & 0.0154 & 0.2414 \\
\hline & Bending & 10 & 4.2616 & 1.9592 & 1.6113 & 3.8384 \\
\hline \multirow[t]{4}{*}{ Humerus } & Compression - proximal end & 11 & 1.2348 & 0.6284 & 1.0336 & 0.6351 \\
\hline & Compression - distal end & 11 & 1.4593 & 0.7369 & 1.2121 & 0.7005 \\
\hline & Tensile & 8 & 3.0035 & 1.6932 & 1.1246 & 3.9545 \\
\hline & Bending & 10 & 2.0971 & 2.5682 & 2.0890 & 6.2033 \\
\hline Radius & Bending & 11 & 2.2988 & 1.0205 & 1.1870 & 1.0415 \\
\hline Ulna & Bending & 12 & 4.4310 & 2.3989 & 1.9730 & 5.7549 \\
\hline
\end{tabular}

${ }^{a}$ The number of specimens is noted after the application of Chauvenet criteria.

The average values in the tensile and bending trials were found to be statistically different $(p=0.08)$ to those in the compression trial. This was probably due to the fact that the specimens in the compression trial were cut at the bone ends where trabecular structure was concentrated, as opposed to the specimens in the bending and tensile trials, which were cut mid-zone and therefore have a cortical coating (Ulrich and van Rietbergen 1999; Yang et al 1999; Brinckmann et al 2002). The average values for the tensile and bending trials are given in Figure 7.

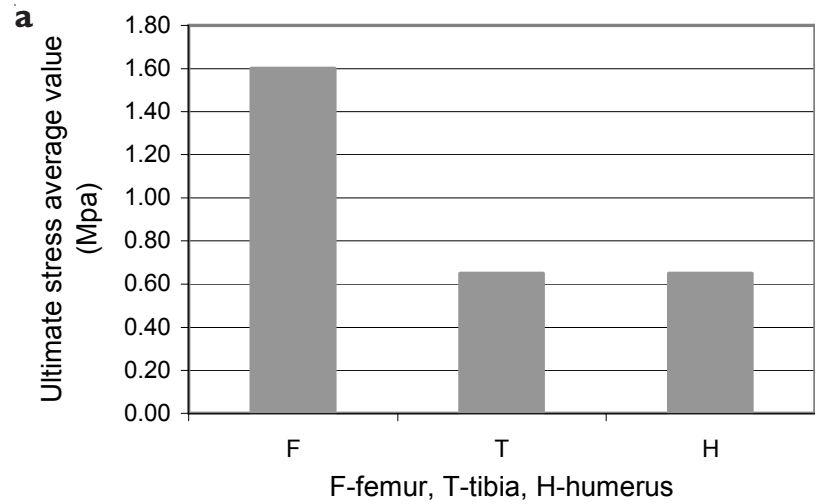

b

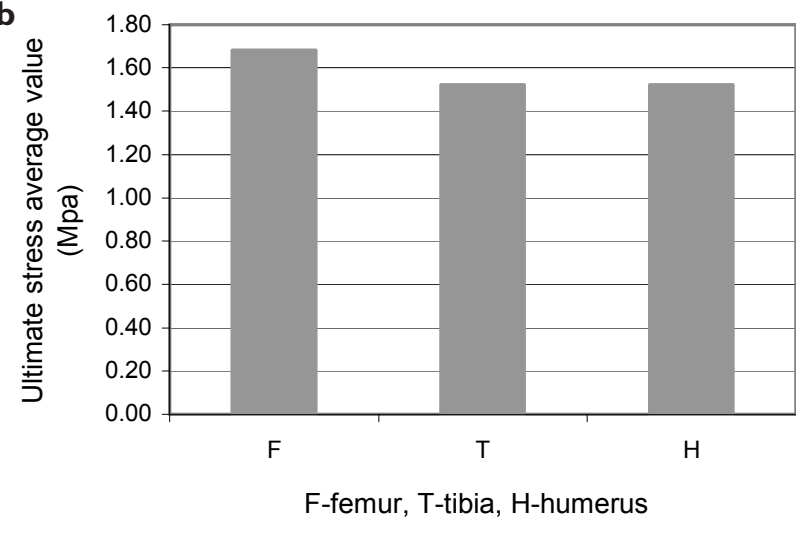

Figure 6 Comparison between the average results in the compression trial: (a) proximal end; (b) distal end.
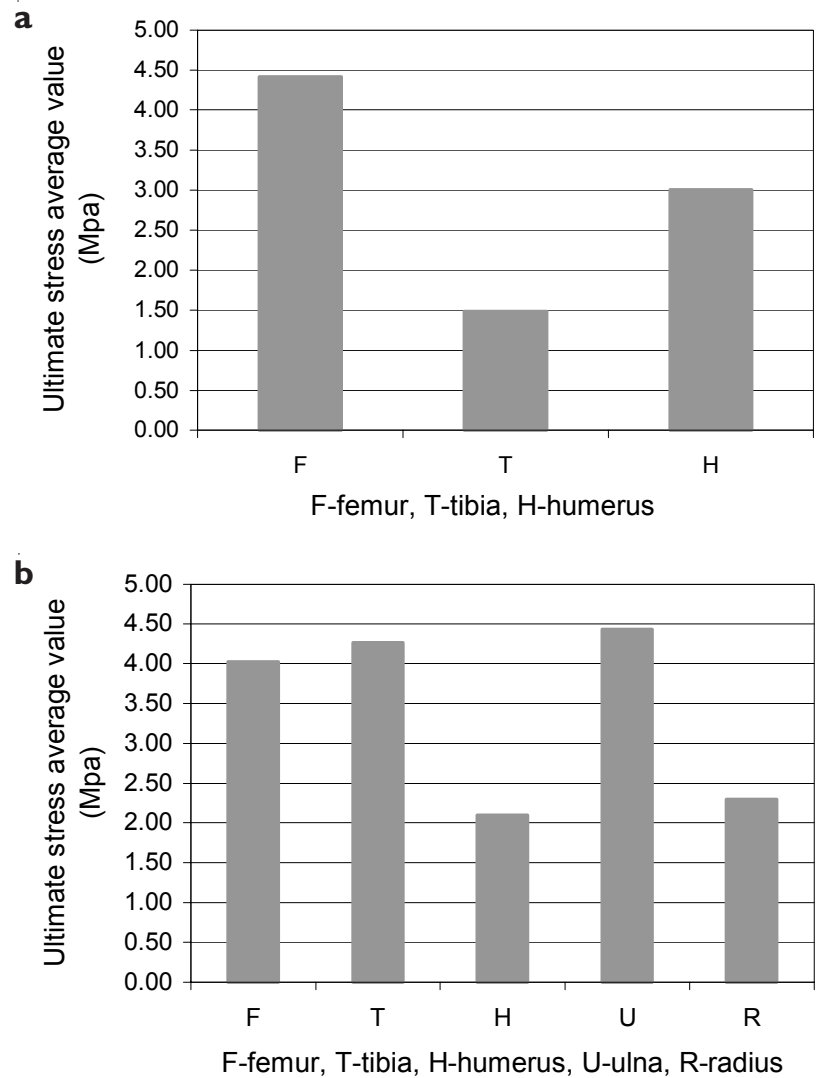

Figure 7 Average results in the tensile (a) and bending (b) trials. 
Table 3 Polynomial regressions fitting the variation of ultimate stresses

\begin{tabular}{|c|c|c|c|}
\hline Bone & Test & Polynomial regression & $R^{2}$ \\
\hline \multirow[t]{4}{*}{ Femur } & Compression - proximal end & $y=-0.0011 x^{6}+0.0318 x^{5}-0.3625 x^{4}+2.0207 x^{3}-5.6654 x^{2}+7.4168 x-2.6765$ & 0.9959 \\
\hline & Compression - distal end & $y=-0.0015 x^{6}+0.0448 x^{5}-0.5053 x^{4}+2.7783 x^{3}-7.6581 x^{2}+9.9582 x-4.1842$ & 0.9928 \\
\hline & Tensile & $y=-0.0444 x^{5}+0.8322 x^{4}-5.8237 x^{3}+18.749 x^{2}-26.356 x+13.15$ & 1 \\
\hline & Bending & $y=-0.0761 x^{3}+1.2293 x^{2}-2.8043 x+3.7155$ & 1 \\
\hline \multirow[t]{4}{*}{ Tibia } & Compression - proximal end & $y=0.0003 x^{4}-0.0063 x^{3}+0.0377 x^{2}-0.0275 x+0.2564$ & 0.9962 \\
\hline & Compression - distal end & $y=-0.0024 x^{3}+0.0523 x^{2}-0.1288 x+0.7469$ & 0.9795 \\
\hline & Tensile & $y=-0.0117 x^{5}+0.1716 x^{4}-0.8575 x^{3}+1.6126 x^{2}-0.4453 x+0.275$ & 1 \\
\hline & Bending & $y=-0.0186 x^{5}+0.24 x^{4}-1.1643 x^{3}+2.8542 x^{2}-2.7689 x+3.0137$ & 1 \\
\hline \multirow[t]{4}{*}{ Humerus } & Compression - proximal end & $y=-0.1164 x^{4}+1.3332 x^{3}-5.0627 x^{2}+7.6742 x-3.3461$ & 1 \\
\hline & Compression - distal end & $y=-0.0003 x^{5}+0.0094 x^{4}-0.0893 x^{3}+0.3536 x^{2}-0.3613 x+0.6004$ & 0.9551 \\
\hline & Tensile & $y=-0.2389 x^{3}+1.3894 x^{2}-0.7245 x+0.3672$ & 1 \\
\hline & Bending & $y=-0.0078 x^{6}+0.1852 x^{5}-1.7106 x^{4}+7.8888 x^{3}-19.041 x^{2}+22.707 x-9.7792$ & 1 \\
\hline Radius & Bending & $y=0.0025 x^{6}-0.0839 x^{5}+1.0621 x^{4}-6.4166 x^{3}+19.204 x^{2}-26.151 x+14.685$ & 0.9815 \\
\hline Ulna & Bending & $y=0.0003 x^{6}-0.0093 x^{5}+0.1256 x^{4}-0.8549 x^{3}+3.0896 x^{2}-4.7452 x+3.6721$ & 0.9891 \\
\hline
\end{tabular}

\section{Discussion}

By performing an F-test analysis on all experimental values after the removal of outlying results, similar conclusions as those given by the variance values in Table 3 were found:

- high correlation (criteria value of 0.8799 ) between the results of the compression test for the two ends of humerus;

- good correlation (criteria value of 0.7935 ) between the results of the compression test for the two ends of femur;

- low correlation (criteria value of 0.0383 ) between the results of the compression test for the two ends of tibia;

- very low correlation (criteria value of 0.0169 ) between the results of the bending test on radius and ulna.

The conclusions of the F-test analysis are confirmed by the graphical representation of all results given in Figures 8, 9, 10 and 11. The differences between the curves in Figure 10 seem greater than the differences in Figure 11, and the corresponding values of F-test criteria are in an inverse order.

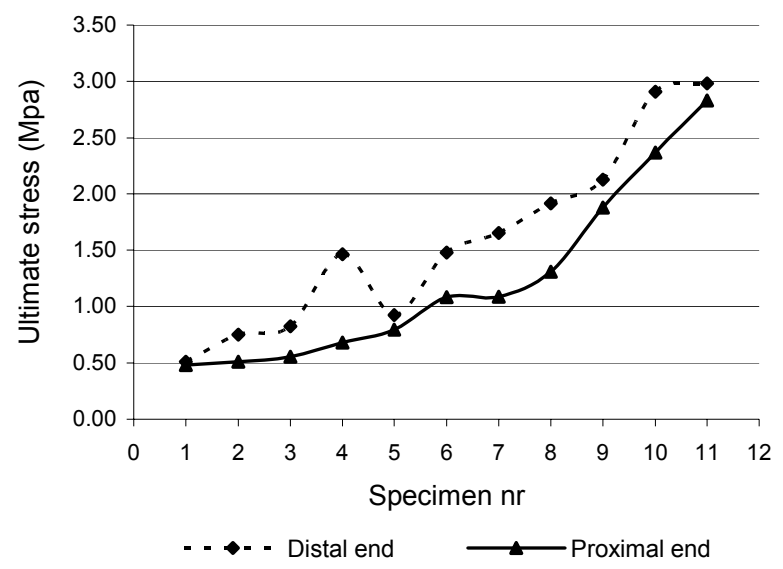

Figure 8 Results of the humerus compression trial.
The apparent inadequacy is given by the difference in scale on the vertical axes (maximum $3 \mathrm{MPa}$ in Figure 10 because the maximum value of experimental ultimate stress in compression of tibia distal end was $2.501 \mathrm{MPa}$, and maximum value $9 \mathrm{MPa}$ in Figure 11 because the maximum value of experimental ultimate stress in bending of ulna was $8.014 \mathrm{MPa})$.

The authors observed that the results in the compression trial of the femur's ends correspond to the results presented by Dvir (2000), assumed from Carter and Hayes (1976) for a similar bone density but for a strain rate of $0.01 \mathrm{~s}^{-1}$.

To use the results for the prognosis of different bones' mechanical behaviours, polynomial regressions were established and are given in Table 3 together with the $R^{2}$ value. The values of the $R^{2}$ estimator very close to 1 prove the correctness of the polynomial functions established for the variation of ultimate stresses for all types of trials.

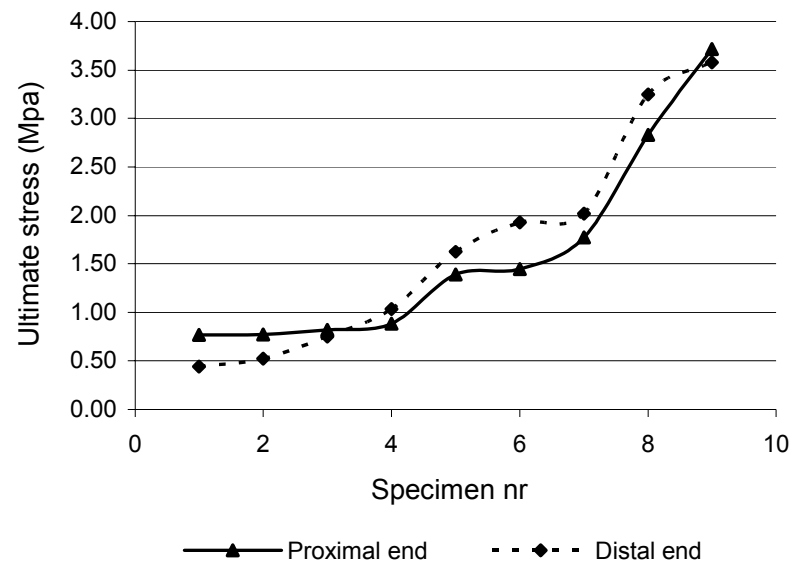

Figure 9 Results of the femur compression trial. 


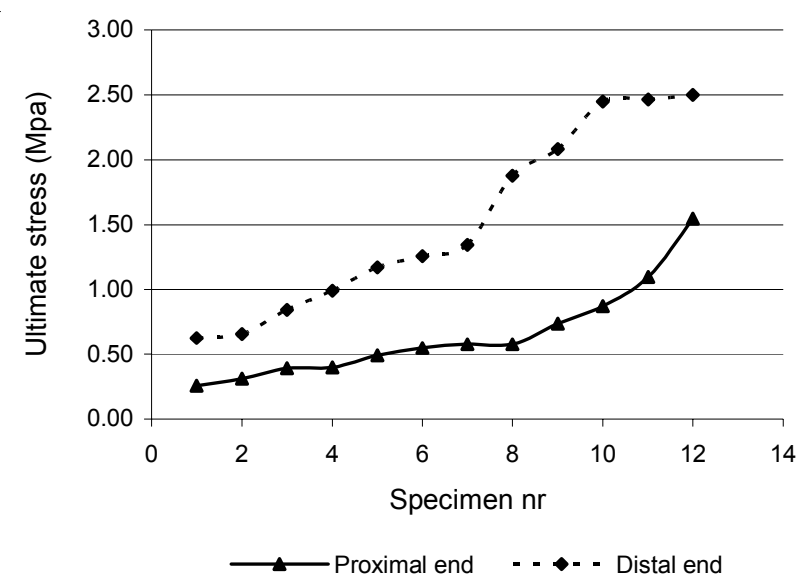

Figure 10 Results of the tibia compression trial.

Any technical application such as designing an implant for a broken bone, designing an artificial joint between two bones of a limb, establishing the type of screw to fix an implant, conceiving an external prosthetic device for a limb, and using an external distractor to correct a limb's architecture can make use of these regressions, which fit the real data almost perfectly.

The regressions could also be used to compare the mechanical behaviour of different bones. The advantages are given by the fact that the regressions are known as analytical functions on which different mathematical calculus can be performed, and they provide immediate and more accurate information than the average values.

By comparing the polynomial representations of the compression test (Figure 12), the differences between the values at the proximal ends (where the femur is the most resistant) are significant. At the distal ends, for $76.8 \%$ of specimens, the conclusion is the same as for the proximal ends; but for the rest, the results have practically the same values. No significant difference between tibia and humerus

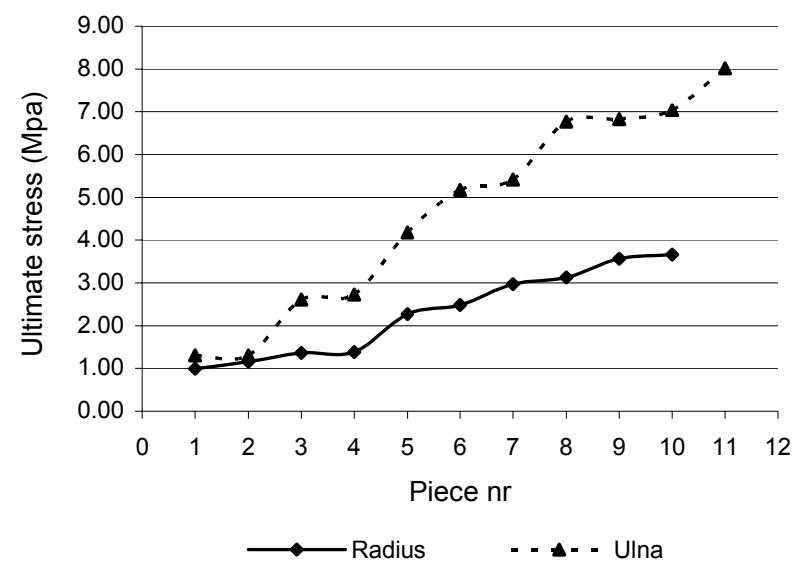

Figure I I Results of the radius and ulna bending trial.
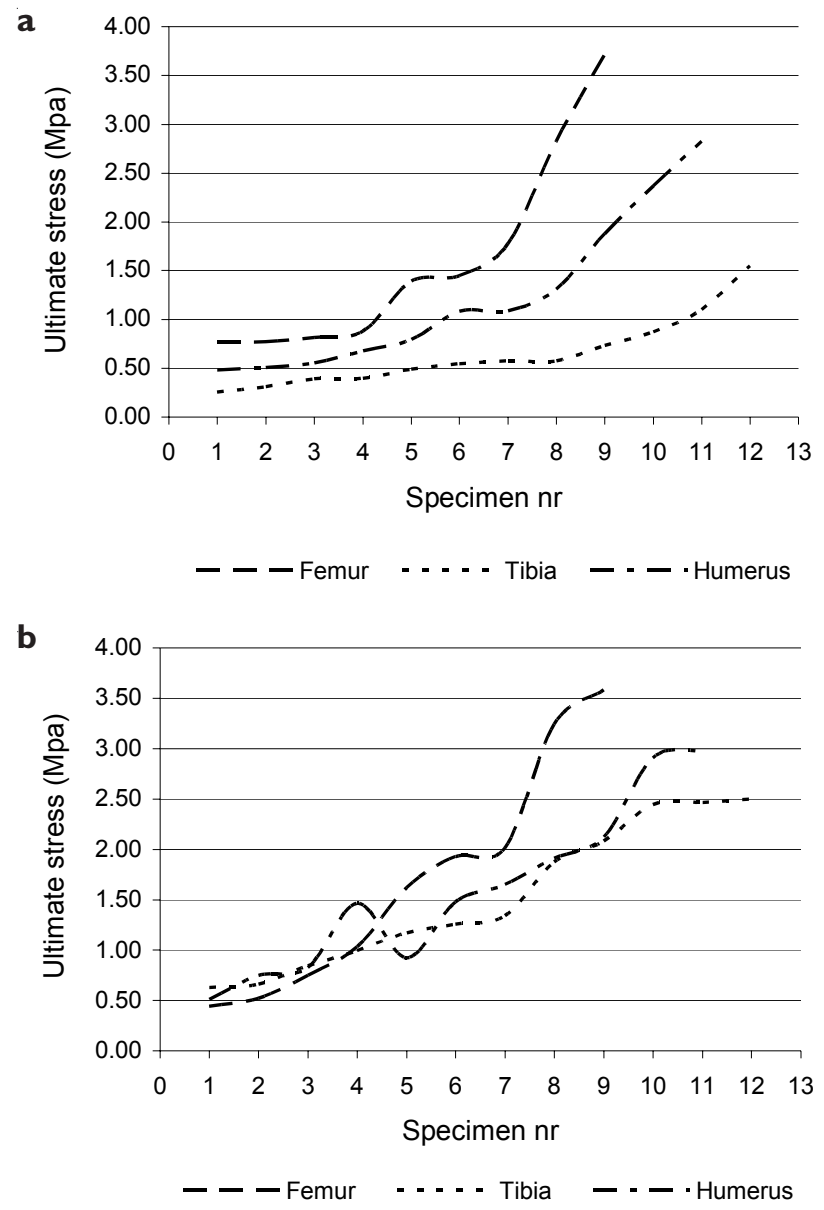

Figure 12 Comparison between the results in the compression trial: (a) proximal end; (b) distal end.

at the distal ends $(p=0.23)$ was found. Comparing the results for femur and tibia, there were significant differences between the curves achieved for compression $(p=0.05)$. The authors agree with the conclusion of Morgan et al (2003): the degree of anisotropy, much more significant for the proximal tibia than the proximal femur, could be a cause of the different behaviour.

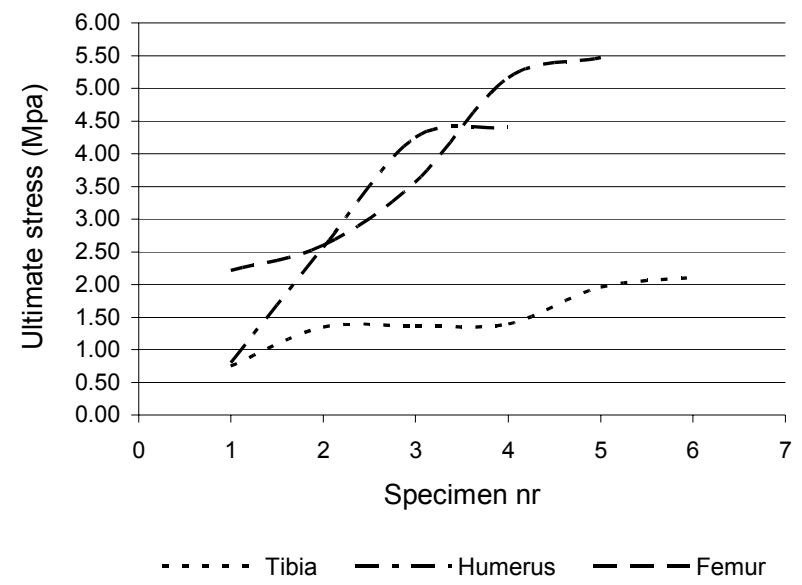

Figure 13 Comparison between the results in the tensile trial. 
Table 4 Verification of Panjabi's equation

\begin{tabular}{|c|c|c|c|c|c|}
\hline Test & Panjabi's equation $^{\mathrm{a}}$ & $\begin{array}{l}\text { Density } \\
\left(\mathrm{g} / \mathrm{cm}^{3}\right)\end{array}$ & $\begin{array}{r}\text { Strain rate } \\
\left(s^{-1}\right)\end{array}$ & $\begin{array}{r}\text { Strength } \\
\text { computed value } \\
(\mathrm{MPa})\end{array}$ & $\begin{array}{r}\text { Average value of } \\
\text { measured stress } \\
(\mathrm{MPa})\end{array}$ \\
\hline Compression & $\sigma_{c}=69.0 \times(\text { strain rate })^{0.06} \times(\text { density })^{2.0}$ & 0.175 & 0.001 & 1.3961 & $1.3584^{\mathrm{b}}$ \\
\hline Tensile & $\sigma_{t}=69.0 \times(\text { strain rate })^{0.06} \times(\text { density })^{2.0}$ & 0.31 & 0.001 & 4.3810 & $3.2726^{\mathrm{c}}$ \\
\hline Bending & $\sigma_{b}=21.6 \times(\text { density })^{1.65}$ & 0.31 & - & 3.1275 & $3.4221^{\mathrm{d}}$ \\
\hline
\end{tabular}

${ }^{a}$ Panjabi and White (2001).

${ }^{\mathrm{b}}$ Global average value for femur, tibia and humerus.

${ }^{\mathrm{c}}$ Global average value for femur, tibia, humerus, ulna and radius.

${ }^{\mathrm{d}}$ Global average value for femur, tibia, humerus and ulna.

In the tensile trial (Figure 13), no significant differences were found between the femur and humerus $(p=0.16)$, but significant differences were found between these two bones and the tibia $(p=0.21)$. In the bending trial (Figure 14), two distinct groups can be seen: the femur and tibia; and the humerus, radius and ulna. The bones belonging to the lower limb have a greater resistance to bending than the bones of the upper limb.

The results achieved by the authors were used to partially verify the equations presented by Panjabi and White (2001), which compute compression and tensile strength by using the bone density and strain rate (see Table 4). The authors propose to change the equation for tensile stress considered by Panjabi and White (2001) to the same as the equation for compression, by replacing the coefficient 69.0 with the coefficient 52.0, with which the computed value is 3.3016 MPa. The proposition is due to the actual difference between the bone behaviours in the compression and tensile trials.

\section{Ackowledgements}

Funding was provided by the Romanian Ministry of Education and Research, Grant nr 02-6-PA-346, National

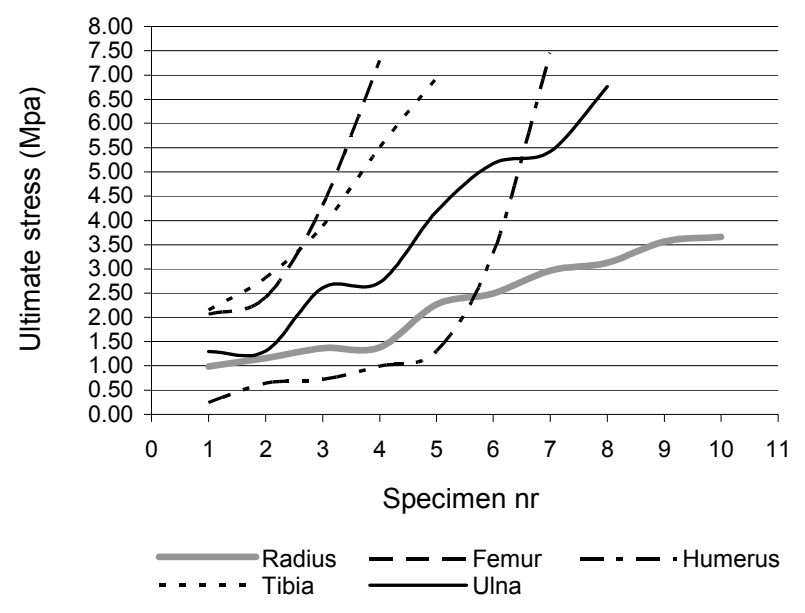

Figure 14 Comparison between the results in the bending trial.
Program PNCDI-Biotech. The research was performed in the Multiple Users Research Center-CMPICSU, funded by World Bank through Romanian National University Research Council, in Politehnica University of Timişoara, Romania.

\section{Notes}

In response to one of our reviewer's suggestions, the authors will do a parametric analysis of the results by investigating the bones of younger subjects.

\section{References}

Abendschein W, Hyatt GW. 1970. Ultrasonics and selected physical properties of bone. Clin Orthop, 69:294-301.

Bonfield W, O'Connor P. 1978. Anelastic deformation and friction stress of bone. J Mater Sci, 13:202-7.

Brinckmann P, Frobin W, Leivseth G. 2002. Musculoskeletal biomechanics. Germany: G Thieme Verlag.

Carter DR, Hayes WC. 1976. Bone compressive strength: the influence of density and strain rate. Science, 194:1174-6.

Carter DR, Spengler DM. 1978. Mechanical properties and composition of cortical bone. Clin Orthop, 135:192-217.

Dvir Z. 2000. Clinical biomechanics. New York: Churchill Livingstone.

Hansson T, Roos B. 1980. The influence of age, height and weight on the bone mineral content of lumbar vertebrae. Spine, 5:545-51.

Lanyon LE, Hampson WG, Goodship AE et al. 1975. Bone deformation recorded in vivo from strain gauges attached to the human tibial shaft. Acta Orthop Scand, 46:256-68.

Lindahl O. 1976. Mechanical properties of dried defatted spongy bone. Acta Orthop Scand, 47:11-19.

Morgan EF, Bayraktar HH, Keaveny TM. 2003. Trabecular bone modulusdensity relationships depend on anatomic site. J Biomech, 36: 897-904.

Panjabi MM, White AA. 2001. Biomechanics in the musculoskeletal system. New York: Churchill Livingstone.

Pope MH, Outwater JO. 1972. The fracture characteristics of bone substance. J Biomech, 5:457-65.

Reilly DT, Burstein AH, Frankel VH. 1974. The elastic modulus for bone. $J$ Biomech, 7:271-5.

Ulrich D, van Rietbergen B, Laib A et al. 1999. The ability of threedimensional structural indices to reflect mechanical aspects of trabecular bone. Bone, 25:55-60.

Wall JC, Chatterji SK, Jeffery JW. 1979. Age-related changes in the density and tensile strength of human femoral cortical bone. Calcif Tissue Int, 27:105-8.

Yang G, Kabel J, van Rietbergen B et al. 1999. The anisotropic Hooke's law for cancellous bone and wood. J Elast, 53:125-46. 


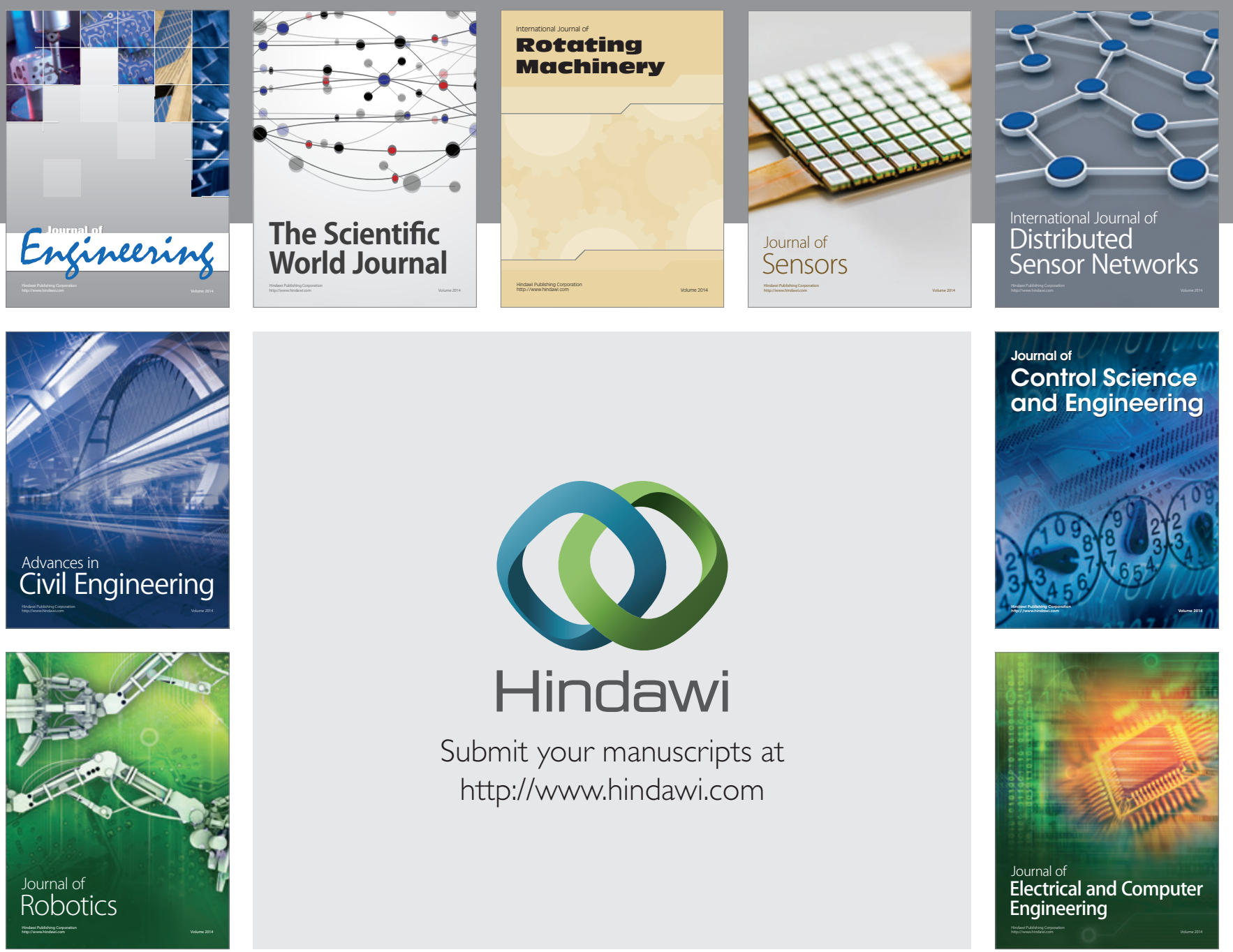

Submit your manuscripts at

http://www.hindawi.com
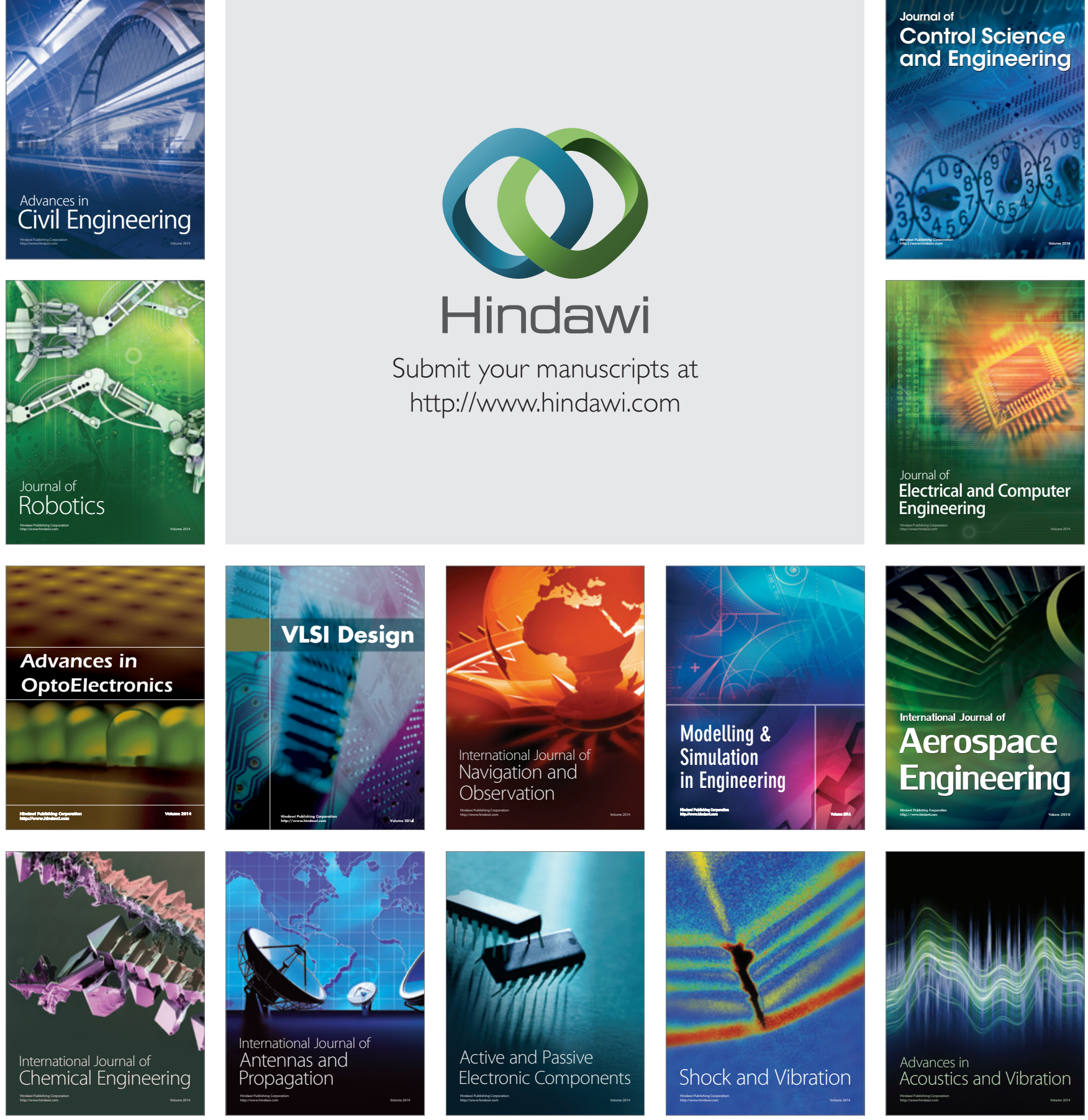